Proceedings of the International Symposium on Physics of Materials (ISPMA 14), September 10-15, 2017, Prague

\title{
Metal-Ceramic Composite Material Used in Shroud Seals for the Steam Turbine
}

\author{
A.A. Smyslov*, N.V. Berdin And I.P. Semenova \\ Ufa State Aviation Technical University, 12 K. Marx St., Ufa, Russia
}

\begin{abstract}
The results of the analysis of the composite material used in shroud seals operating under elevated temperature and high-frequency vibration for a long time are presented. The key object of the paper is to provide for high conformability together with mechanical strength of the composite under selection of both composition and dispersion of the powder, as well as by achieving the adjustable porosity. The composite samples were obtained by cold pressing of $\mathrm{Fe}-13 \% \mathrm{Cr}-2 \%$ Mo powder containing surface developed particle shapes combined with ceramic additives with further sintering and heat treatment. The specified residual porosity of the composite is demonstrated. The experimental research results of "compatibility" of the composite of different structures contacting the engaged element of the steam turbine blade are given.
\end{abstract}

DOI: 10.12693/APhysPolA.134.757

PACS/topics: metal-ceramic composite, microstructure, residual porosity, strength, hardness, compatibility

\section{Introduction}

Shroud seals providing radial clearance between the turbine rotor and stator both for combined heat power and hydro-electric power plants are greatly affected by reheated steam, vibration and flow-accelerated corrosion. Indeed, when operating under emergency situations the standard seals are affected by blade elements damaging both the seal itself and mating parts [1]. Abraded seal whose tightness is provided for by blade tip protrusions making slots in the abraded sealing material is one of such seals. Turbine gland seals are made, for example, from braided metal fibers, honeycombs or sintered metal particles and applied by thermal spraying of the powdered material, etc. [1-3]. Conformability of such seals is due to their high porosity and low strength. However, shroud seals for steam turbine blades operating under elevated temperature and high-frequency vibration for a long time should possess both high conformability and high mechanical strength and wear resistance.

Powder made of high-alloyed and rust-resisting steel is proposed herein for high strength and wear resistance, and good conformability was achieved by making adjustable porosity in the material through adhesive bonding between the surface-developed particles. The metalceramic composite was obtained by cold pressing of steel powder with further high sintering and heat treatment. The resulting structure of the metal-ceramic material affecting deformation under contact with the involved blade element (compatibility) is studied.

\section{Materials and experimental procedure}

The samples were made of rust-resisting $\mathrm{Fe}-13 \% \mathrm{Cr}-$ 2\%Mo steel (Russian analogue H13M2) powder with 100

\footnotetext{
*corresponding author; e-mail: alex.smyslov@mail.ru
}

to $160 \mu \mathrm{m}$ particles obtained by hydride-calcium method. Shapes of metal powder particles are presented in Fig. 1a.

To ensure consistent dissolving of oxide layers and better sintering of particles along the boundaries, $6 \% \mathrm{BaSO}_{4}$ was added to the mixture. It interacts with the iron under sintering making sulfides eutectics melting at $800-$ $850^{\circ} \mathrm{C}$ [4]. Two types of high-temperature additives were used as "the solid lubricant": $5 \%$ of $\mathrm{CaF}_{2}$ and boron nitride (BN) up to $6 \mathrm{wt} \%$. The components were mixed for $3 \mathrm{~h}$. Zinc stearate was used as a plasticizer. The powder blend was exposed to cold pressing at about $500 \mathrm{MPa}$ by DE2432-01 hydraulic press to get the compacted material. Powder composites were sintered in the electric furnaces under an inert atmosphere (argon) at $1200^{\circ} \mathrm{C}$ [4].

Microstructure of samples was studied through JSM6490LV scanning electron microscope equipped with INCAx-act model 51-ADD0009 X-ray detector. The Brinell test was made by the hardness-testing machine with a $5 \mathrm{~mm}$ steel ball as the indenter. Round $5 \mathrm{~mm}$ samples were tested in tension by INSTRON equipment at the operation temperature of the steam turbine blade of $600^{\circ} \mathrm{C}$ with a strain rate of $10^{-3} \mathrm{~s}^{-1}$. Compatibility was evaluated by engagement of the tool simulating the blade element made of high-chromium steel (see Fig. 1b).
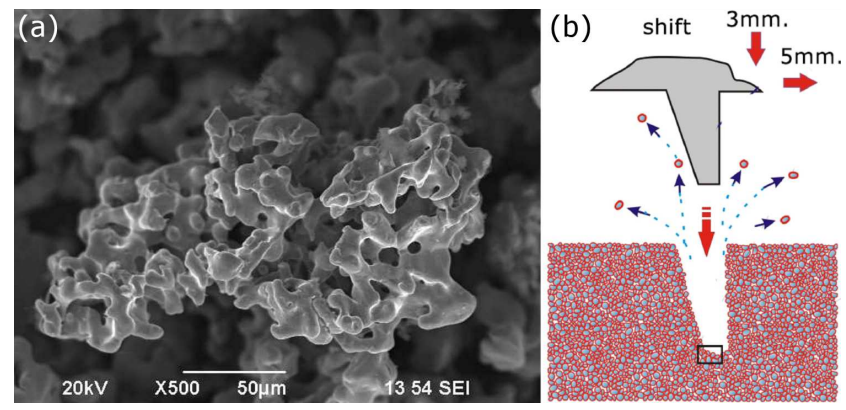

Fig. 1. Shape of steel powder particles (a), engagement of the simulating tool with the sample (b). 


\section{Results and discussion}

\subsection{Microstructure and residual porosity of the composite samples}

Images of the structure of the sintered composite without the solid lubricant (Fig. 2a), with $\mathrm{CaF}_{2}$ added (Fig. 2b) and BN added (Fig. 2c) are given in Fig. 2.

Figure 2 shows that minimum residual porosity was observed for sintering of the powder with no additives (Fig. 2a). There are no clear boundaries between separate particles due to their melting during sintering.
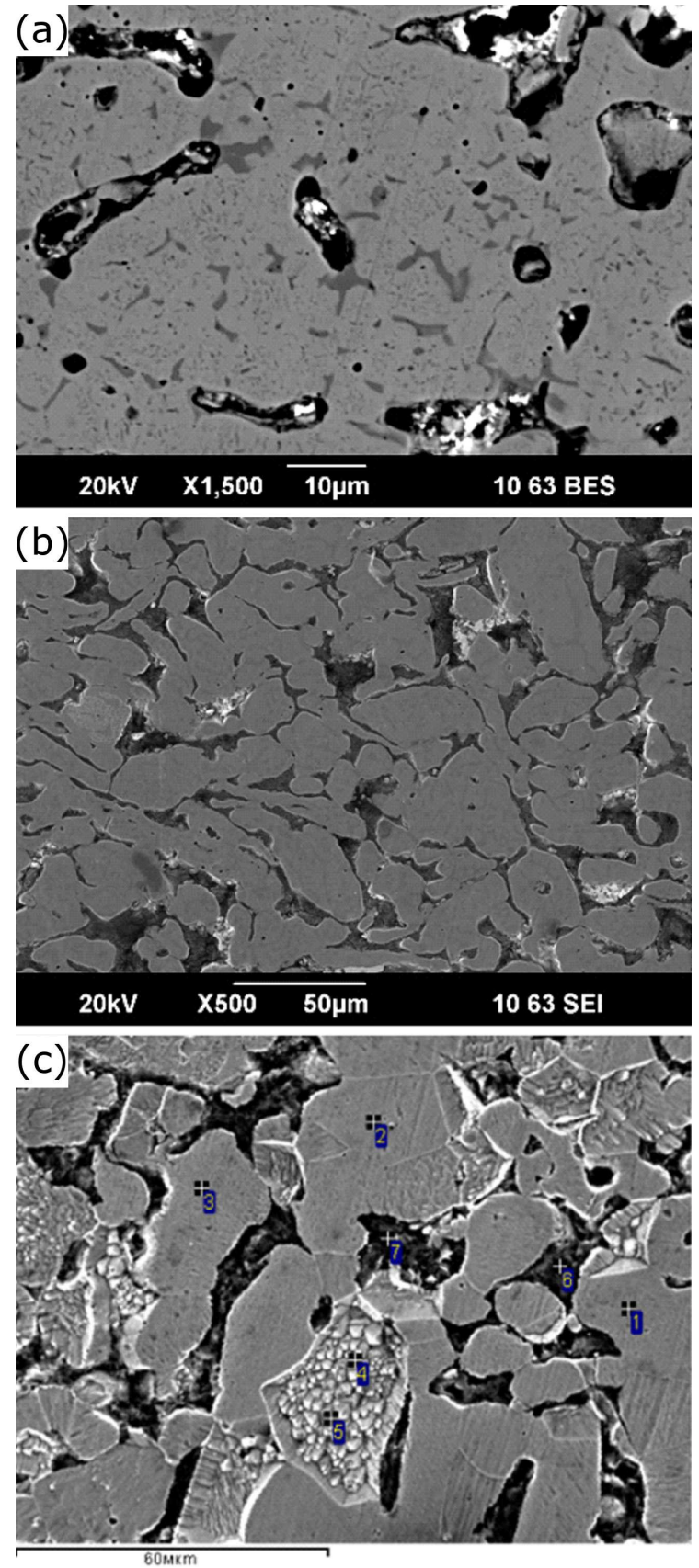

Fig. 2. SEM micrograph of the sintered metal powder structure: (a) without the solid lubricant, (b) with $5 \%$ $\mathrm{CaF}_{2}$ added, (c) with $6 \% \mathrm{BN}$ added.
The number of pores is substantially larger at sintering with $\mathrm{CaF}_{2}$ as the solid lubricant, with the powder particles having distinct boundaries, thereby enabling particles separation under engagement of the tool (Fig. 2b). Boundaries of particles are clearly seen in the structure of the composite sample with BN added, and a great number of pores are filled with the solid lubricant (Fig. 2c). Boron nitride found in the pores after sintering and thermal treatment is likely to be due to $\mathrm{BN}$ high melting temperature (up to $3000^{\circ} \mathrm{C}$ ) as compared with $\mathrm{CaF}_{2}$, because this compound is keeping its hexagonal structure up to $1150^{\circ} \mathrm{C}[5]$.

\subsection{Mechanical properties and sample conformability}

The results of mechanical testing and HB hardness of composite samples made by sintering with no additives and with the solid lubricant are presented in Table I. The composite samples sintered from steel powder with no additives are seen to have the highest hardness and ultimate strength at $600^{\circ} \mathrm{C}$. This may be explained by high adhesion strength of the sintered particles due to their boundaries melting (Fig. 2a). Increase of the residual porosity in samples with the solid lubricant added results in strength reduction from 300 to $200 \mathrm{MPa}$ if $\mathrm{CaF}_{2}$ is added, and to $110 \mathrm{MPa}$ - if $\mathrm{BN}$ is added. Higher hardness of $\mathrm{HB}$ sample with boron nitride is likely to be stipulated by the fact that part of the pores was filled with the solid lubricant.

Mechanical properties of the composite

TABLE I samples based on steel powder

\begin{tabular}{c|c|c|c}
\hline \hline $\begin{array}{c}\text { Mechanical } \\
\text { properties }\end{array}$ & No additives & $5 \% \mathrm{CaF}_{2}$ & $6 \% \mathrm{BN}$ \\
\hline hardness $[\mathrm{HB}]$ & 130 & 90 & 120 \\
\hline $\begin{array}{c}\text { ultimate strength } \\
\text { at } 600^{\circ} \mathrm{C}[\mathrm{MPa}]\end{array}$ & $220-320$ & $150-200$ & $50-110$
\end{tabular}

The results of the experiment for the composite material compatibility obtained with no additives and with the solid lubricant added are given in Fig. 3. When steel powder with no additives is sintered and the residual porosity is minimal, the material is heated and deformed after the tool engagement (Fig. 3a). Melted boundaries of the sintered particles are likely to make removal of particles impossible under the engagement. Warming up both of the composite material and the engaged tool is found in the sample with $\mathrm{CaF}_{2}$ added with fair residual porosity, and therewith separate particles are sintered and stick to the engaged element (Fig. 3b).

Slipping of some particles with respect to each other, detachment and removal takes place under the tool engagement in $\mathrm{BN}$ sample when the residual pores are filled with high temperature solid lubricant, without warming up both of the composite material and the tool being engaged (Figs. 2c and 3c). 

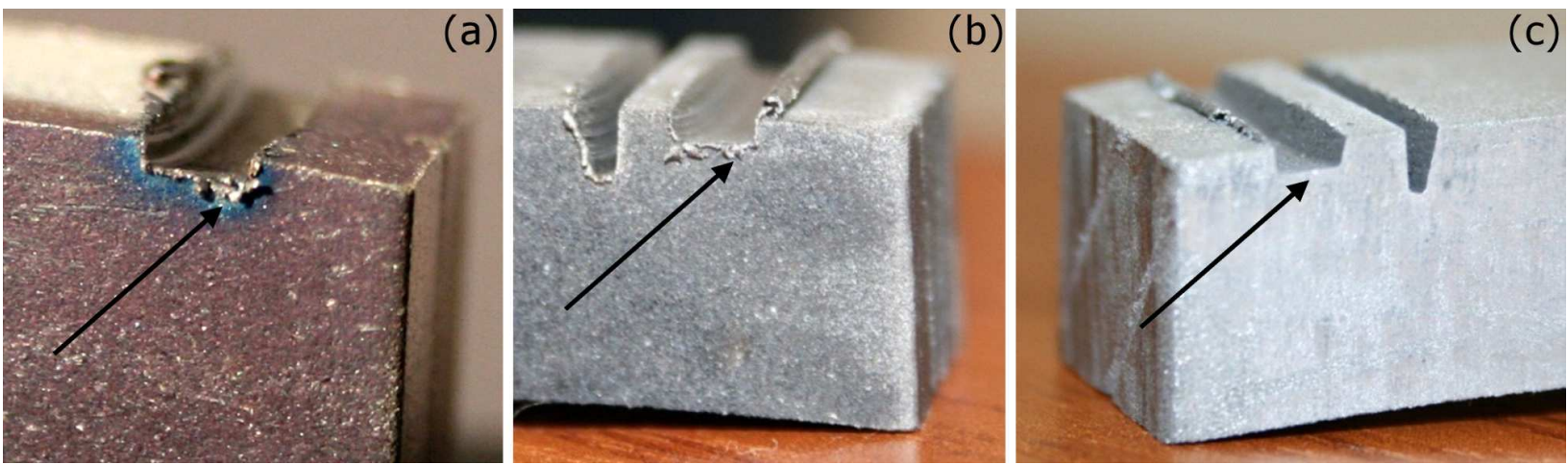

Fig. 3. Composite material samples after compatibility testing: (a) with no solid lubricant added, (b) with $5 \% \mathrm{CaF}_{2}$ added, (c) with $6 \% \mathrm{BN}$ added.

Therefore, the process of seal conformability consists of sequence of separate processes of the filler particles detachment due to adhesion strength reduction over the boundary of each particle. Besides, the particle detachment and removal results in extra heat removal from the affected area and thereby the main part of the material remains unheated.

Application of the composite materials obtained by sintering of the corrosion-resistant steel powder with the boron nitride acting as the solid lubricant enabling combination of high strength properties of the seal with good conformability is the promising approach to increase turbo-machine performance. It should be noted that the application of the composite powder to make some parts of the seal to be conformable is enabling to decrease labor hours in manufacturing sealing inserts considering both shape and construction of such items.

\section{Conclusion}

1. Preparation of the composite material by sintering of the $\mathrm{Fe}-13 \% \mathrm{Cr}-2 \%$ Mo corrosion-resistant steel powder and adding the high-temperature solid lubricant is found to enable making of the residual porosity in the structure providing combination of high hardness and good adhesive strength.
2. The best combination of high hardness and conformability is shown to be demonstrated by the composite material made of steel powder by adding $6 \%$ boron nitride.

\section{References}

[1] V.A. Mel'nik, Chem. Petrol. Eng. 45, 152 (2009).

[2] B. Qiu, J. Li, X. Yan, Proc. IME J. Power Energ. 228, 416 (2014) .

[3] A.O. Pugachev, P. Helm, Proc. IME J. Power Energ. 223, 83 (2009).

[4] A.S. Lisyansky, A.M. Smyslov, A.A. Smyslov, A.D. Mingajev, Patent RF2499144, published 20.11.2013, Russia.

[5] P. Patnaik, Handbook of Inorganic Chemicals, McGraw-Hill, 2002. 